\title{
A Call for an Evidence-informed Criteria Selection to Guide Equitable Health Investments in the Era of Universal Health Care: Policy Analysis
}

\author{
Ma. Esmeralda C. Silva, MPAf, MSPPM, PhD, ${ }^{1,2}$ Ma-Ann M. Zarsuelo, RND, MSc, ${ }^{1,3}$ \\ Marianne Joy N. Naria-Maritana, MD,,$^{1,3}$ Zenith D. Zordilla, MD, ${ }^{1,3}$ Hilton Y. Lam, MHA, PhD, 1,3 \\ Michael Antonio F. Mendoza, DDM, MA,,$^{1,4}$ Ara Karizza G. Buan, RMicro, ${ }^{1,3}$ Frances Karen A. Nuestro, PTRP, ${ }^{1,3}$ \\ Janvic A. Dela Rosa, RND ${ }^{1,3}$ and Carmencita D. Padilla, MD, MAHPS 5 \\ ${ }^{1}$ University of the Philippines Manila Health Policy Development Hub \\ ${ }^{2}$ College of Public Health, University of the Philippines Manila \\ ${ }^{3}$ Institute of Health Policy and Development Studies, National Institutes of Health, University of the Philippines Manila \\ ${ }^{4}$ College of Dentistry, University of the Philippines Manila \\ ${ }^{5}$ University of the Philippines Manila
}

\begin{abstract}
Background. The passage of the Universal Health Care (UHC) Act in the Philippines in early 2019 intensified the need to ensure equitable health investments by the government. Exploring the different criteria and indicators that are used to determine areas that are most in need of health services can help local and national health authorities determine priorities for health investments given finite resources.

Methods. A systematic review of literature on determinants of health equity and other indicators was conducted as pre-work to generate discussion points to the roundtable discussion participated by all major key stakeholders. Shared insights and expertise were thematically analyzed to produce a policy paper with consensus policy recommendations.

Results. Based on the review of the literature and the discussion, indicators (mainly physical inaccessibility and socioeconomic factors) for identifying Geographically Isolated and Disadvantaged Areas (GIDA) in DOH Administrative Order 185, s. 2004 is used to prioritize municipalities for health investments. Review of other policies and guidelines to determine the level of health needs and prioritizing investments yielded to four laddered domains: geographic, population characteristics (e.g., social and cultural determinants of access), health system (e.g., health service delivery), and health status. These domains may provide a more equitable set of metrics for health investment. The Local Investment Plan for Health (LIPH) is the current process used for health-related investments at the local level and may be revised to be more responsive to the requirements set by the UHC Act 2018. Hot spotting to concentrate health services by communities may be a more rapid approach to investment planning for health. Bed capacity as a specific metric in the UHC Act 2018 highlights the need for a review of the Hospital Licensure Act 2004.
\end{abstract}

Conclusion and Recommendations. To aid in determining priorities for health investments, a comprehensive integrated analysis of resources, determinants, and indicators should be done to determine the need and the gaps in the available resources. Innovative strategies can also be best implemented such as mathematical models or formulas. Lastly, current strategies in the development, monitoring, and evaluation of investment planning for health at different levels should be strengthened, expanded, and harmonized with other existing development plans.

Key Words: equity, Universal Health Care, need indicators, health investments

Corresponding author: Ma-Ann M. Zarsuelo, RND, MSc UP Manila Health Policy Development Hub

National Institutes of Health

University of the Philippines Manila

623 Pedro Gil St., Ermita, Manila 1000, Philippines

Email:mmzarsuelo@up.edu.ph

\section{INTRODUCTION}

The Republic Act 11223, otherwise known as the "Universal Health Care (UHC) Act" articulates the State's policy "to protect and promote the right to health of every Filipino and instill health consciousness among them" 
(Section 2). ${ }^{1}$ Furthermore, it also outlines the framework it will adopt to ensure universal health care, including:

a. "An integrated and comprehensive approach to ensure that every Filipino is health literate, provided healthy living conditions, and protected from hazards and risks that could affect their health;

b. A health care model that provides every Filipino access to a comprehensive set of cost-effective and quality promotive, preventive, curative, rehabilitative and palliative health services without causing financial hardship, prioritizing the needs of the population who cannot afford such services;

c. A framework that fosters a whole-of-system, wholeof-government, and whole-of-society approach in the development, implementation, and cognizant of health policies, programs and plans; and

d. A people-oriented approach for the delivery of health services that are centered on people's needs and wellbeing, and cognizant of the difference in culture, values, and beliefs."

\section{Health investments in achieving universal health care}

Section 29 of the UHC Act described the concept of equity which seeks to uphold health care and consequently, where the government should preferentially invest. ${ }^{1}$ Section 29 of the Law states that the "DOH shall annually update its list of underserved areas which shall be the basis for preferential licensing of health facilities and contracting health services." 1 Moreover, the "government shall guarantee that the distribution of health services and benefits provided for in this Act shall be equitable by prioritizing Geographically Isolated and Disadvantaged Areas (GIDA) in the provision of assistance and support."

Equity in health policy decisions is equated with "distribution according to need." However, there remains no consensus on the definition and scope of "need." This is further complicated by the challenge to ensure sensitivity and flexibility to capture what is needed on the ground across time. It is important to keep in mind that the returns to investments in improving the overall health status of Filipinos will not be seen, measured or felt within a short period of time.

Thus, with the government's endeavor toward evidenceinformed policy development, the Department of Health (DOH), contracted the University of the Philippines Manila, as the research team to conduct research and series of roundtable discussions as inputs in the Implementing Rules and Regulations of UHC Act. One of the identified priority policy issues is determining criteria for health equity, which this paper focused on. This position statement aimed for the following: 1) to evaluate different criteria in determining the needs of the Filipinos in terms of health; and 2) to explore what metrics can be used to prioritize health investments. This paper sought to define and operationalize the concept of equity in UHC.

\section{METHODS}

\section{Pre-work research}

Review of literature was conducted to generate scientific and legislative evidence for crafting the policy tools presented at the roundtable discussion. A search through PubMed using the keywords "health equity" showed 16,234 results, "health equity" and "indicators" showed 1,058 results, while "health equity" and "indicators" and "Philippines" yielded seven results. Bibliographies of the articles were also crosschecked to generate further relevant records, yielding 46 articles. For updated reports and white papers, online search of related reports in official sites of government agencies was also conducted, yielding 30 records, composed of manuals, guidelines, and short articles. Related laws on Universal Health Care were retrieved at Official Gazette of the Philippines yielding two executive issuances. Documents and bibliographies were screened by relevance to the topic of interest. A total of 53 records were removed due to duplication. Below is a diagram for the search strategy (Figure 1).

\section{Review of Literature}

Review of literature showed different metrics from international and local evidence that were expounded and contextualized by the insights gathered in the policy discussion. This includes GIDA classification and criteria classified in the domains of the physical environment, population characteristics, health system, and health status. Findings were utilized in generating discussion points and crafting the policy brief presented in the policy discussion.

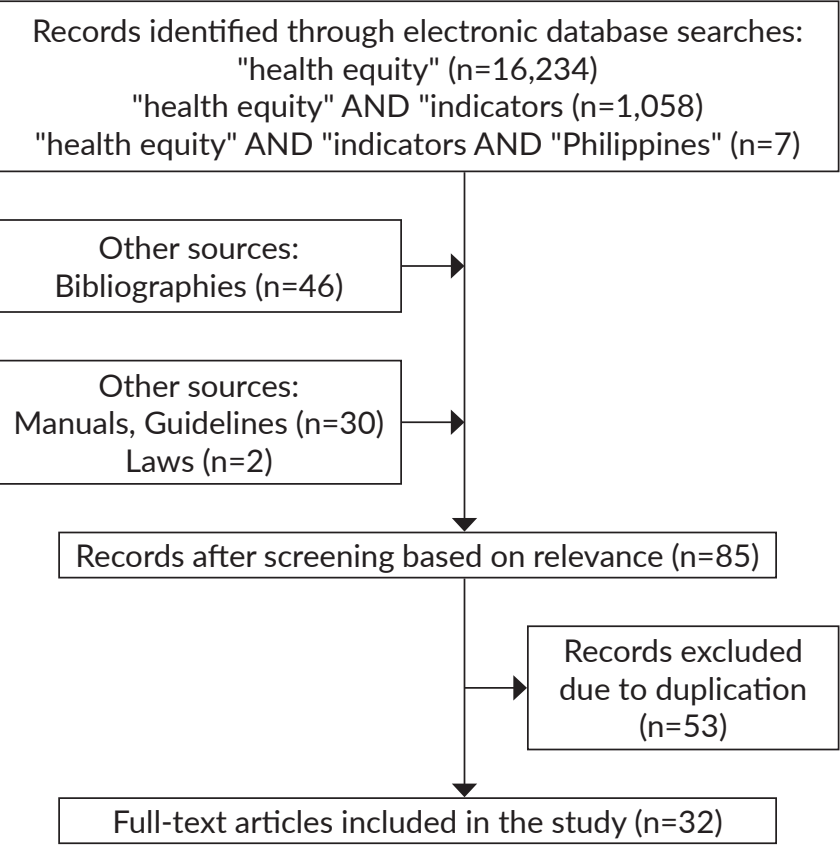

Figure 1. Search Strategy Flow Diagram. 


\section{Metrics for equitable health investments}

\section{Geographically Isolated and Disadvantaged Areas}

In the Philippines, physical access has driven the prioritization of health service delivery at the local level. In 2004, the DOH released AO 185 s. 2004 which provides the framework to guide the identification and classification of municipalities and barangays as Geographically Isolated and Disadvantaged Areas (GIDA). GIDA include "communities with marginalized population physically and socio-economically separated from the mainstream society and characterized by (1) physical factors- isolated due to distance, weather conditions and transportation difficulties (island, upland, lowland, landlocked, remote and unserved/ underserved communities); and (2) socioeconomic factors (high poverty incidence, presence of vulnerable sector, communities in or recovering from situations of crises or armed conflicts)." 3,4 The objectives of establishing GIDA are: "(1) to empower communities, LGUs, and key stakeholders toward good governance for health; (2) to generate LGU and community commitment to manage and sustain health care; (3) to strengthen multi-sectoral linkages through convergence and efficient use of resources; and (4) to improve access and provision of health services." Ultimately, the classification process is to institutionalize and to establish a system for local health development management in these communities to ensure that quality health care services are being provided $^{5}$ Furthermore, the GIDA Health System Development's (HSD) key course action is to extend basic and regular health facility-based services to the populations that are marginalized and areas that are far.

\section{Other criteria from national government agencies and} international non-government organizations

The comprehensive review of the various criteria used by various national government agencies (NGAs) and international non-government organizations (iNGOs) to determine the level of health needs, as well as the government's ability to respond to these needs yielded a total of 32 references. The indicators culled from these references were further organized under the four domains included in the conceptual framework. Table 1 shows the distribution of these indicators across the four domains. These indicators were then presented to the RTD participants who further added inputs based on their field of practice and expertise.

Assessment of the indicators showed that other useful indicators are not currently being used to determine the needs in the country. These include indicators related to cultural access as well as natural and conflict-related indicators. This awareness of the other determinants of need may be considered a positive aspect. The possibility of integrating these metrics across programs and departments may be easier through proper coordination and knowledgesharing. It is interesting to note that the quality of care indicators was not found, particularly for population-based

Table 1. Number of indicators found per domain of needs assessment for health investments

\section{Domain}

Frequency

Geographic / Physical environment

Population Characteristics

Health System

Health Status

Table 2. Identified gaps per domain of indicators on needs assessment in health investments

\section{Domain}

Built environment

Built environment

\begin{tabular}{ll} 
& $\begin{array}{l}\text { services, accessibility to transportation, } \\
\text { and peace and order profile }\end{array}$ \\
\hline $\begin{array}{l}\text { Population } \\
\text { characteristics }\end{array}$ & $\begin{array}{l}\text { Socio-cultural indicators, health-seeking } \\
\text { behavior, cultural access, social access, } \\
\text { social support, and distress } \\
\text { - Educational and employment } \\
\text { opportunities, health literacy }\end{array}$ \\
\hline
\end{tabular}

Health outcomes /

health status

health services. Other gaps in the indicators found in the literature and identified in the roundtable discussion are presented in Table 2.

RA 1939 stipulates the prescribed financial contribution of the national, provincial, and municipal governments in support to providing at least one free general hospital bed for every five thousand population in each province. ${ }^{6}$ In contrast, there were also indicators available only at the national, regional, and provincial levels. The absence of such data at the city and municipal levels hampers the ability of local chief executives and planners to get a bird's eye view of the poverty situation in their localities. Although there are datasets on indigency at the LGU level, these are fragmented, thus, do not give the full picture of poverty in the area. When verified with the participants, the National Household Targeting System (NHTS) and Pantawid Pamilyang Pilipino Program (4Ps) datasets do not capture all poor individuals/households.

Other constructs have been adopted in the country and globally to assess the level of need of a population. According to a study by O'Donnell (2007), at times, even if effective health care interventions exist, there is underutilization of these services. Apart from the physical inaccessibility and socio-economic constraints, the following are noted to be "determinants of preferences for health care: (1) culture and gender; (2) knowledge and education; and (3) demand responses to poor quality service. 7

\section{Proposed guidelines for determining needs for health investments}

From the review of literature, the UPM HPDH research team proposed a four-tier pyramid, demonstrating the 
prioritization of different clusters of factors that can influence the health status of a population; a guide for identifying criteria in determining inequities in health (Figure 2). The framework is made up of four levels representing four domains that can be influenced and/or controlled by the government.

At the bottom of the pyramid are the indicators involving the physical/ built environment which includes geographic location, ecological conditions, communication and electricity services, accessibility to transportation, Water, Sanitation and Hygiene (WASH) indicators, distance from healthcare facilities, hazards exposure, and peace and order. The succeeding domain level focuses on population characteristics including socio-cultural indicators, educational opportunities, social support, social distress, employment status, opportunities, and demographics. This part of the pyramid also includes economic and human capital. The health system cluster includes indicators related to the health facility resources, accessibility to healthcare, service availability, health service delivery, leadership and governance, health financing, and human resources. The top-most domain focuses on population-level health outcomes/ health status. This includes mortality ratio and rates, $\mathrm{MCH}$ statistics, nutrition-related indicators, immunization status, incidences of communicable and non-communicable diseases, vectorborne diseases, reproductive healthcare services, and healthseeking behavior. ${ }^{8-22}$

For accurate targeting of the beneficiaries (subpopulation or population-wide), all domain levels must be considered with increasing priority as the level goes higher. All domains are interrelated and exert influence, controlled or not, with one another. Hence, policy reforms must recognize capturing all cluster indicators (internal and external) to optimize achieving better health outcomes.

\section{Roundtable discussion (RTD)}

The UP Manila Health Policy Development Hub (UPM HDPH) committed to being at the forefront of generating evidence-informed and inclusive health policy recommendations. Hence, UPM HPDH, as the research team, in collaboration with the Department of Health $(\mathrm{DOH})$, as the primary agency, conducted research and policy stakeholders' discussion with the shared goal to produce evidence as inputs to the Implementing Rules and Regulations of the UHC Act. The first in the series of roundtable discussions was held on the $2^{\text {th }}$ of November 2018 at Board Room, Philippine General Hospital, Manila. Key representatives from the national government agencies, academe, private sector, and international funding agencies, professional societies, and nongovernment organizations were critically identified and approved both by the research team and primary agency, to participate in the discussion to deepen the participants' understanding of the policy issue.

The ultimate goal of the policy RTD was to generate consensus recommendations for strategic policy reforms brought by the UHC Law. The first half of the event was devoted to getting various perspectives from selected presenters. The policy brief was presented by a member of UPM HPDH that outlined the current gaps, policies, and presented the four-tiered pyramid tool in identifying criteria on equity, subjected to comments of all discussants. Followed by a resource speaker from $\mathrm{DOH}$ who provided the structural legislative evidence and updates on the performance of health programs. Having set the insights on the national level, a key resource speaker, Municipal Health Officer from Pampanga, shared the health resource allocation in the LGUs in the lens of an MHO.

From the deliberation of the research and primary agency on the specific discussion points for the policy issue of interest, the RTD was driven by the following discussion questions: 1. What are the good practices and challenges in the current process in determining the needed health investments at the provincial, city, and local levels?

2. In the light of adopting a set of metrics to help in deciding where and how health investments should be made, what are the considerations in prioritizing or shortlisting the available and recommended metrics out there?

3. What are the major characteristics of the envisioned decision-making process that should be adopted?

\section{Policy analysis}

The shared insights, evidence, and recommendations during the RTD were thematically analyzed to produce a

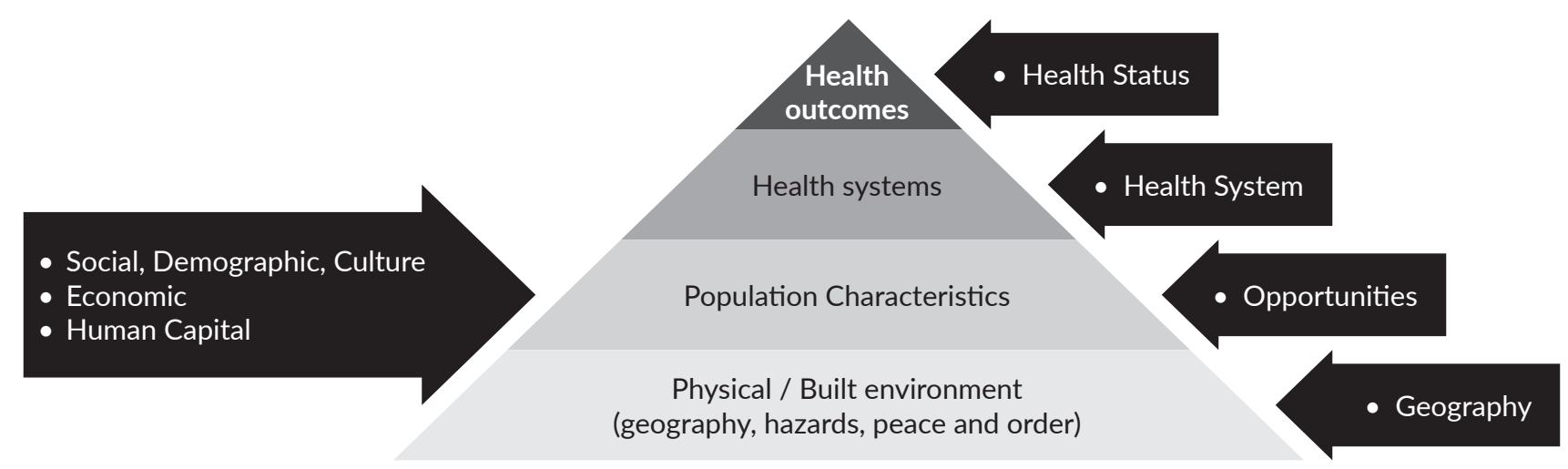

Figure 2. Major clusters of indicators to determine the need for health investments. 
policy paper. To guarantee that policy recommendations are consensus among all discussants, the draft paper was circulated to all participants for comments and/or approval. Revisions were applied in response to the consolidated inputs. The paper was then reviewed by UPM HPDH members, then by the Chancellor who also issued the approval. Participants were informed that the RTD proceedings will be published through correspondence and during the RTD. This included consent that their names and respective organizations will be listed in the Acknowledgment section.

\section{RESULTS AND DISCUSSION}

During the discussion, key concepts for equitable health investments that emerged were Local Invest Plan for Health (LIPH), Hospital Licensure Act of 2004 for bed capacity, and 'hot-spotting,' which could be revisited and amended in light of the UHC Act implementation.

\section{Key concepts for Health Investment Planning}

\section{A. Local Investment Plan for Health as the main guide for health investments for LGUs}

Before the passage of the UHC Act, the LIPH is the main decision-making process that guides local health executives in spending on the health needs of the local constituents. LIPH is a participatory health investment planning process that covers a three-year planning horizon. It aims to do the following: (1) serve as the localization tool of national health programs; (2) use as the basis for resource mobilization and investment planning towards attaining local and national health goals; and (3) official means for $\mathrm{DOH}$ and development partners to engage LGUs. Each LIPH includes the identification of the health needs of the locality through consultation with stakeholders. It will then propose an overall health strategy and propose specific interventions, to be developed into an operational plan. Indicators will be identified and used for regular performance monitoring. Planning and costing matrices shall be included in the LIPH. It is designed to organize and consolidate the areas for health investments at the provincial, city, municipal, and barangay levels. Ideally, the planning process emanates from the barangay level and is subsequently consolidated at the municipality, city, and eventually provincial levels, respectively. The LIPH is a document that has enabled local chief executives to rationalize and focus on much-needed investments in their localities. Representatives from the $\mathrm{DOH}$ shared that the monitoring of the LIPH is constantly being strengthened. Having an updated LIPH is now part of the LGU scorecard.

\section{Strength and Weaknesses for the investment process}

That the LIPH is already in place may be considered a strength. Local executives are already familiar with the process and may need some re-adjustments to accommodate changes with the UHC Act. Given that the UHC Act is moving towards a re-centralization of the local health system at the provincial level, it is important to have a system in place that efficiently consolidates information on health system performance, resources available within the province, as well as the gaps in these. These can serve as baseline data upon which improvements may be made.

$\mathrm{DOH}$ representatives also shared that they are working on linking various national-level plans (e.g. for health facilities and HRH) and the LIPH with the vision of consolidating the needed investments in the LGU from the DOH. Unfortunately, this is only limited to healthrelated investments.

On the sensitivity of LIPH in determining the health needs of the population, LGU participants shared that the local health statistics are integrated into the process of updating the LGU's LIPH. However, several weaknesses were identified. One of which is on the planning process of several LGUs which have been more procedural and driven by compliance. The need to make the process more evidencedriven was emphasized. Another aspect is the adjustments in the projected investments that are being made at various levels to fit available resources. The drawback of making this type of adjustment is that higher-level authorities and bilateral/multilateral agencies do not get a sense of what is still needed.

Another weakness is that the plan does not fully capture the demand for health care. Corollary to this is the lack of equity-related indicators. This refers to the disaggregation of health data by some inequity indicators (e.g. household income, classification as indigent, GIDA classification). This constrains local planners from systematically integrating equity concerns into the planning process for LIPH. A participant raised that an equity-based tool should be included in planning.

A challenge to the LIPH is that it focuses on healthrelated investments, failing to capture investments in other sectors. An LGU participant shared a related challenge where despite the municipality's capacity to provide timely and updated health reports and potential connectivity between barangays, they are handicapped by the existing poor telecommunications network in the area. This holds true for investments in other sectors such as road and telecommunication infrastructure and other social determinants of health.

Since the LIPH involves a multi-stage planning process that emanates from the barangay up to the provincial level, participants shared that there are still significant barriers to the adoption and implementation of activities in the LIPH at the different LGU levels. This was attested by a participant sharing that the politicized process of adoption of their city/ municipal LIPH by the provincial government. This is largely driven by the fact that there are many municipalities/cities that are competing over a fixed pot of resources. This is further compounded by the limited 
capability of local health planners to conceive an evidencedriven LIPH, as well as the presence of weak monitoring and evaluation (M\&E) systems present on the ground.

Lastly, the timing of the LIPH planning process and that of the national health budget remains to be a challenge. This has resulted in the inability of the national health budget to fully reflect the local health investment needs.

The LGU's health system performance is assessed through the LGU scorecard. However, it was emphasized that the scorecard needs to be improved wherein output and outcome indicators should be the focus, rather than input indicators.

When it comes to the specific monitoring and evaluation of the LIPH, there are existing M\&E processes within the $\mathrm{DOH}$. However, participants identified some challenges in M\&E of implementing LIPH. At present, it was reported that no system tracks the outcomes (i.e. quality issues) vis-à-vis the health investments that were made. Nevertheless, there are currently multiple health information systems at the national level that could be tapped. It was emphasized that there should be an avenue through which the outputs and outcomes of the LIPH are continuously monitored and evaluated.

\section{B. Hot spotting as a decision-making tool for health investment}

In the study of Holzer et al. (2014), hot spots were defined as "sources of high hospital costs" a geographical location which where most of the hospital costs come from. ${ }^{23}$ This can be a community or even a small set of households located in a single place that availed most of the hospital services over a certain period of time. Throughout their study, Holzer et al. identified hot spots as specific addresses where costs are the highest identified through the use of hospital data identifying a patient's address. ${ }^{24}$ Hot spotting can be used as a tool for identifying areas that need more health services than others.

Through hot spotting, the government would be able to save resources by targeting investments instead of blinding investing in all locations. It can ensure the maximum utilization of the health services in a certain area, perhaps increase the return of investments for the hospitals and health care service facilities, and improve the overall health of the community. ${ }^{24}$ Furthermore, through the aid of hot spotting, the general health of a community considered as a "hot spot" can easily be measured and identified. Other relevant factors such as the socio-economic situation concerning health can also be identified to improve community health. ${ }^{24}$

To maximize the accessibility of health services, a "hot spot" density map can be utilized by the government. This map must contain indicators or determinants that affect health such as social factors like, socio-cultural and economic factors (e.g. community class, income rates and the number of families, birth rates, teenage pregnancy and degree of health care use). Another would be the types of disease and the age of the patients who availed government services. The comprehensiveness of using a hot spot density map can give clarity and understanding of the medical situation of an area. This provides the opportunity to compare one area with other areas to perhaps improve local health services.

In the Philippines, it can be argued that hot-spotting is somehow similar to the Department of Health's GIDA. According to the DOH, GIDA includes communities with a population that is marginalized and socio-economically and physically detached from mainstream society. ${ }^{25}$ Physical factors include being isolated due to transportation difficulties, specifically, "landlocked, hard to reach, lowland, upland, island, and unserved/underserved communities." Socioeconomic factors include being a community experiencing or recovering from armed conflict or crisis, having a vulnerable sector, or a high incidence of poverty, thus, the inability to afford health commodities. ${ }^{26}$

\section{Proposed criteria for determining hot spot area mechanisms for publishing and updating.}

Three criteria can be considered in determining a hot spot, first would be the frequency of which people would avail health services in a specified area. It is imperative to identify how the services that the catchment population mostly availed and how frequently they are availed. This is consistent with the study of Yang et al. (2006), identifying the demand for the health service to provide more supply of the said health service. ${ }^{25} \mathrm{~W}$ ith this, the government can efficiently service the people based on what they exactly need and better allocate resources and budget.

The second criteria would be the social and economic factors of the area. It is important to note that the composition of the population could determine public health service utilization. People coming from the poorest of the poor often utilize government health services compared to the richer segment of the population. Over $77.3 \%$ of the poor population sought health services of the government and rarely go to a private hospital for health services. ${ }^{27}$ This is mainly attributed to the affordability and the subsidies provided by the government hospitals as the patients are financially constrained. ${ }^{28}$

At the population level, there are existing health and social welfare needs assessment processes such as NHTS and 4Ps. These are widely implemented at the LGU-level as the bases for programs such as the Medical Assistance Program (MAP). However, some participants reported that these listings are incomplete and inaccurate. They shared that there were implementation issues, particularly in identifying individuals and families who needed medical and/or welfare assistance. When it comes to identifying indigents at the community level, some participants shared that there were instances at the LGUs that the identification process was not properly implemented. This has resulted in reported instances of mistargeting individuals and households. Some participants reiterated that these gaps have 
led to leakages in the provision of health and social welfare assistance to those who are in need.

The third criterion would be the distance of the health service facility. This translates to the geographical inaccessibility as a barrier in utilizing public health services, which posit health risk. This can also consequently negate the positive health-seeking behavior of the population. On average, it will take 39 minutes to reach health service facilities in the Philippines but to avail more complex health service, travel time can take longer, particularly for those in rural areas. ${ }^{29,30}$ In the case of Maternal, Newborn and Child Health and Nutrition (MNCHN) of the Department of Health, it is stated in their Manual of Operations that Basic Emergency Obstetric and Newborn Care (BEmONC) should be established no more than 30 minutes away from the residence of the catchment population and the Comprehensive Emergency and Newborn Care (CEmONC) should be no more than 60 minutes away from the BEmONC facility. CEmONC can perform the services of $\mathrm{BEmONC}$ as well as provides additional services like cesarean, blood banking, blood transfusions, and other highly specialized obstetric interventions. If the travel time of the people to reach health care services is more than two hours, then it is already categorized as having poor accessibility. ${ }^{31}$ By bringing services on health closer to the community, people can be encouraged to make use of the government health facilities and to promote community participation in improving the overall health of the area.

Physical accessibility is but one of the many criteria used at the national, regional, and local levels to determine and prioritize the various needs of Filipinos, including health needs. There was a consensus that there is a need to expand this to include inequities in the physical and built environments. A DOH representative shared that the office is working on updating the AO 2004-185 to reflect the drivers of inaccessibility such as social and cultural access factors.

Possibilities of building a model that would guide the process of identifying needs were raised during the discussion. This model could be multi-step, a "lean" mathematical model or a model that is based on the life course approach. One suggestion is the creation of a model that would initially define and identify underserved areas. Ecological conditions are then tacked in the model and, lastly, the profile of the more vulnerable populations. Other metrics that were discussed included wellness indices, patient-related outcomes, disease patterns, and service quality indicators.

\section{Bed capacity as a metric and the need to revise the Hospital Licensure Act 2004}

The UHC Act also identified bed capacity in public health facilities as a metric for identifying underserved areas.

A DOH representative shared that their Bureau is currently wrapping up its update on the Philippine Health Facility Development Plan which can be one of the bases for triangulating the needed bed capacity. However, it was consistently brought up during the discussion that the assessment of bed capacity at the LGU level should include public and private facilities.

All hospitals are required to be licensed as per Republic Act 4226, otherwise known as the "Hospital Licensure Act" as amended in 2004. The law served as the basis of how hospitals should be established and certain guidelines which it should follow to get a license to operate. However, the law failed to include external factors of public health as part of the licensing process. It appears that the licensing process concerns only the technical side of establishing health facilities as it focuses only on the internal facility, equipment, sanitation, etc., in its assessment. The licensure process does not assess the needs of its local population. Similarly, the process of PHIC accreditation of hospitals is also limited to improving facilities with no regard for public health or participation of the local residents. ${ }^{32}$ Moreover, increasing the bed capacity via legislation is also a limiting factor that needs to be reviewed, revised, and possibly to support Senate Bill 1143 which gives the authority to do so to the $\mathrm{DOH} .{ }^{32}$

One thing that can be done to streamline the licensing process is to include the needs of the community - linking the social and economic situation to the health services provided. Using the community as a basis for establishing the correct scale of health facilities can improve efficiency because it can bolster the participation of the residents.

The government can also increase its gains from health facility investments as there will be a constant demand based on the public need. Since health service providers will be physically accessible to residents, there will be less burden to avail the services needed, particularly among the poorer members of the community. This is in line with hot spot density mapping.

\section{CONCLUSION AND RECOMMENDATIONS}

The formula in attaining equity requires balancing and including all complex determinants of health access and availability at the macro and micro levels of the population. The first step forward is to determine the needs of Filipinos, cross-examined and contextualized at the different settings of sub-populations. Different indicators in assessing the needs of Filipinos in terms of health were reviewed and discussed with major stakeholders. These indicators were grouped into domains such as built environment, population characteristics, health systems, and health outcomes which are hoped to portray a holistic picture of equity.

To aid in the decision-making process that could be adopted in determining the need and how health investments should be allocated, using a comprehensive integrated analysis of resources, determinants, and indicators should be done. Current strategies in the development, monitoring, and evaluation of investment planning for health at different levels need to be strengthened, expanded, and harmonized with other existing development plans. 
Based on the review of literature and policy discussion, the following are recommended:

1. To conduct a comprehensive integrated analysis of available local health resources to determine the gaps (i.e. physical access, socio-cultural access, financial access, hazard exposure, availability, and quality issues) as well as to aid in the prioritization of health investments. It should include both publicly provided and privately provided health resources.

2. To include social determinants and other indirect indicators of health to refine and expand the metrics to be used in the identification and prioritization of underserved areas.

3. To implement innovative strategies in determining underserved areas for health investments. Formulating a prioritization process could be made by:

a. Including all areas for investment through a thorough and accurate needs assessment then develop exclusion criteria to determine which are not systematically identified as "underserved" areas; and

b. Formulating multi-step mathematical model through the systematic analysis of equity indicators and rank the indicators in identifying underserved areas.

4. To strengthen and expand current strategies in the development, monitoring and evaluation of investment planning for health at the barangay, municipality, city, and provincial levels.

a. To include evidence-informed investment planning in light of the movement towards a province-wide integration of local health systems. Multiple health information systems that are in place for the various vertical health programs need to be consolidated and interconnected. This will strengthen the loop between $\mathrm{M} \& \mathrm{E}$ and investment planning over the medium- and short-term. Also, local health planners can recalibrate strategies and realign investments more quickly with this set-up.

b. To synchronize the local planning for health not only with the national budget planning cycles but with the other existing local plans of the municipality/ city (e.g. comprehensive land use plans). By integrating the health plan in the CLUP, disadvantaged areas will be given enough attention as far as spatial factors are taken into consideration.

c. To ensure that all needed health programs will be available to all LGUs to address health service accessibility, eliminating patient transfer to areas outside of their province. This should be supported by adequate health human resources and infrastructural investment.

5. To harmonize the local health investment plans with other local development plans that LGUs are mandated to update and implement such as the CLUP, Local Development Plan, and the Annual Investment
Plan. This ensures that investments in non-health infrastructures and services are put in place to directly or indirectly enhance and strengthen the accessibility and availability of needed health investments, especially by those who need these the most.

\section{Statement of Authorship}

All authors participated in data collection and analysis, and approved the final version submitted.

\section{Author Disclosure}

The authors declare no conflicts of interest.

\section{Funding Source} HPSR.

This project was funded by the DOST DOH AHEAD-

\section{REFERENCES}

1. Republic of the Philippines. Republic Act 11223. An Act Instituting Universal Health Care for All Filipinos, Prescribing Reforms in the Health Care System, Amending for The Purpose Certain Laws, Appropriating Funds Therefore and for Other Purposes; 2018.

2. Capuno JJ, Kraft AD. Equity in education and health services in the Philippines [Internet]. 2018 [cited 2018 Oct 15]. Available from: https://www.researchgate.net/profile/Joseph_Capuno/ publication/283300503_Equity_in_education_and_health_services_ in_the_Philippines/links/5631e61908ae13bc6c3588fc/Equity-ineducation-and-health-services-in-the-Philippines.pdf.

3. Robertson R. What is community disadvantage? Understanding the issues, overcoming the problem [Internet]. Child Family Community Australia. 2011 [cited 2018 Oct 11]. Available from: aifs.gov.au.

4. Zuellig Family Foundation. Impetus [Internet]. 2016 [cited 2018 Oct 11]. Available from: https://zuelligfoundation.org/wp-content/ uploads/2016/07/HeleconProceedings_20160617.pdf.

5. Department of Health. Geographically Isolated and Disadvantaged Areas (GIDA) [Internet]. n.d. [cited 2018 Oct 10]. Available from: https://www.doh.gov.ph/node/1153-1158.

6. Republic Act No. 1939 [Internet]. 1957 [cited Oct 2018]. Available from: https://www.lgu.ph/listings/republic-act-no-1939/service capacity management.

7. O'Donnell O. Access to health care in developing countries: breaking down demand side barriers [Internet] Reports in Public Health. 2007 [cited 2018 Oct 10]. Available from: https://www.scielosp.org/scielo. PhP?script=sci_arttext\&pid=S0102311X2007001200003.

8. Telehealth Act of 2012, HB. 636, 15th Cong., 2nd Sess. 2012.

9. Philippine eHealth Systems and Services Act, SB. 1618, 17th Cong., 2nd Sess. 2017.

10. Kröger H, Pakpahan E, Hoffmann R. What causes health inequality? A systematic review on the relative importance of social causation and health selection. Eur J Public Health. 2015 Dec; 25(6):951-60. doi: 10.1093/eurpub/ckv111.

11. Caballes A. Human Resources for Health and Philippine Policy Options. Acta Med Philipp. 2009 Jul-Sep; 43(3):49-57.

12. Hodge A, Firth S, Bermejo R, Zeck W, Jimenez-Soto E. Utilisation of health services and the poor: deconstructing wealth-based differences in facility-based delivery in the Philippines. BMC public health. 2016 Jul; 16:523. doi: 10.1186/s12889-016-3148-0.

13. Human Resources for Health Country Profiles: Philippines [Internet]. World Health Organization [cited 2018 Oct 11]. Available from: https://apps.who.int/iris/bitstream/handle/10665/207680/ 9789290616245_eng.pdf? sequence $=1$ \&isAllowed $=\mathrm{y}$

14. Halili S, Cristobal F, Woolley, T, Ross S, Reeve C, Neusy AJ. Addressing health workforce inequities in the Mindanao regions 
of the Philippines: Tracer study of graduates from a sociallyaccountable, community-engaged medical school and graduates from a conventional medical school. Med Teach. 2017 Aug; 39(8):859-65. doi: 10.1080/0142159X.2017.1331035

15. Primary Care In Philippine Health Professions Education: The School Of Health Sciences Approach. Lecture presented at University of the Philippines [Internet]. n.d. [cited 2018 Oct 11]. Available from: https://www.google.com/url?sa=t\&source=web\&rct=j\&url=htt ps://www.nast.ph/index.PhP/downloads/category/131-stakeholdersmeeting-on-training-objectives-for-primary-care-in-the-philippines \%3Fdownload\%3D516:primary-care-in-phil-health-prof-ed-u\&ved=2ahUKEwj3rtWHz4LnAhWUfd4KHYiNA6YQFjAAegQIBBAB \&usg=AOvVaw3Tgzn3HrxHMTu4sdUOErln

16. Reorganizing the Ministry of Health, Integrating the Components of Health Care Delivery Into its Field Operations, and for Other Purposes, EO. 851, s. 1982.

17. Zuellig Family Foundation. (2017). Reducing health system fragmentation through improved leadership and governance: Annual and Sustainability Report [Internet]. 2017 [cited 2018 Oct 10]. Available from: https://zuelligfoundation.org/wp-content/ uploads/2018/05/ZFF-Annual-and-Sustainability-Report-2017.pdf

18. JICA. Partners in Nation Building: Annual Report [Internet]. 2018 [cited 2018 Oct 17]. Available from: https://www.jica. go.jp/philippine/english/office/others/c8h0vm0000d3hsdw-att/ report_2018.pdf

19. PHILDHRRA. Annual Report [Internet]. 2008 [cited 2019 Aug 16]. Available from: http://i.phildhrra.net/application/ files/1214/7928/1259/2008_PhilDHRRA_Annual_Report.pdf

20. Guidelines in the Preparation for Availment and Processing of DOH Health Facilities Enhancement Program (HFEP) Projects for FY 2016, DO. 2015-0287, Department of Health. 2015.

21. Philippine eHealth Systems and Services Act, SB. 1618, 17th Cong., 2nd Sess. 2017.

22. Department of Health. Rural Health Midwives Placement Program (RHMPP) / Midwifery Scholarship Program of the Philippines (MSPP) [Internet]. [cited 2019 Aug 13]. Department of Health; Available from: https://www.doh.gov.ph/rural-health-midwivesplacement-program
23. Son HH. Equity in Health and Health Care in the Philippines [Internet]. 2011 [cited 2018 Oct 9]. Available from: https://papers. ssrn.com/sol3/papers.cfm?abstract_id=1616951.

24. Holzer J, Canavan M, Cherlin E, Bradley E. Health Hot Spots: Mapping Hospital Costs and Social Determinants of Health. Open J Prev Med. 2014 Sep; 4(9):717-22. doi:10.4236/ojpm.2014.49081.

25. Yang DH, Goerge R, Mullner R. Comparing GIS-based methods of measuring spatial accessibility to health services. J Med Syst. 2006 Feb; 30(1):23-32. doi:10.1007/s10916-006-7400-5.

26. Department of Health. Administrative Order (AO) 185 series 2004. Establishment of GIDA in support of Local Health Systems Developments; 2004.

27. Department of Health. The Philippine Health System at a glance [Internet]. [cited 2018 Sep 7]. Available from: https://www.doh.gov. $\mathrm{ph} /$ sites/default/files/basic-page/chapter-one.pdf.

28. Department of Health. Administrative order no. 2007-41 Guidelines on the mandatory allocation of a certain percentage of the authorized bed capacity as charity beds in private hospitals [Internet]. 2007 [cited 2018 Oct 10]. Available from: https://hfsrb.doh.gov.ph.content/ uploads/2018/09/ao2007-0041.pdf.

29. National Statistics Office. Philippine Demographic and Health Survey 2008. 2008 [cited 2018 Oct 6]. Available from: https:// dhsprogram.com/pubs/pdf/FR224/FR224.pdf.

30. Senate Bill 1143. DOH Hospital Bed Capacity Rationalization Act [Internet]. 2016 [cited 2018 Oct 10]. Available from: https://www. senate.gov.ph/lis/bill_res.aspx?congress=17\&q=SBN-1143.

31. Department of Health. The MNCHN Manual of Operations 2nd Edition. National Center for Disease Prevention and Control San Lazaro Compound, Rizal Avenue, Sta. Cruz, Manila, 1003 Philippines [Internet]. 2011 [cited 2018 Oct 10]. Available from:

32. Senate Bill 1143. DOH Hospital Bed Capacity Rationalization Act [Internet]. 2016 [cited 2018 Oct 10]. Available from: https://www. senate.gov.ph/lis/bill_res.aspx?congress=17\&q=SBN-1143. 